\title{
新しいだ円切削装置の開発*
}

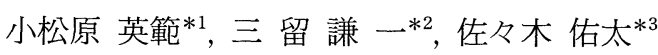

\section{A New Cutting Machine for Elliptical Cylinder}

\author{
Hidenori KOMATSUBARA*4, Ken-ichi MITOME and Yuuta SASAKI
}

\author{
${ }^{* 4}$ Department of Mechanical System Engineering, Yamagata University, \\ 4-3-16 Jonan, Yonezawa-shi, Yamagata, 992-8510 Japan
}

\begin{abstract}
About 100 years ago, Dr. Franz Reuleaux invented the elliptical chuck which made it possible to cut elliptical cylinder in the same as cutting cylinder. This was invented on basis of turning block double slider crank mechanism. For this reason, this chuck had a problem of causing vibration as the rotational speed increased. Therefore, this mechanism could not been put into practical use. In order to overcome this weak point, one of the authors invented a new type of cutting machine for elliptical cylinder. In this paper, first the principle of new cutting machine is described. Next this machine is designed and made for trial. Finally two elliptical cylinders are made for trial and measured by roundness tester. Experiments prove that the principle of the new cutting machine holds true, principle of mechanism of cutting elliptical cylinder, and shows fundamental characteristics of this machine and its possibility for practical utility.
\end{abstract}

Key Words: Machine Element, Cutting, Elliptical Machine, Oldham Coupling, Fixed Centrode, Moving Centrode

\section{1. 緒言}

約 100 年前に Dr. Franz Reuleaux は, だ円加工の ためにだ円チャックを考案した(1).だ円チャックの利 点は，旋盤で真円を切削するのとほぼ同様の方法で, たやすくだ円を加工できることであった. しかし，回 り両スライダ機構を用いているため, スライダと溝と の間ですべり摩擦が発生するという問題や, 被削物を フラフープ運動させるため, この運動が振動を誘発さ せるという問題があった ${ }^{(2)}$. そして, これらの問題が 加工精度に悪影響を与えることや機構の複雑さゆえ に, 実用化には至らなかった ${ }^{(3)}$.

現在のだ円加工としては主に, ならい装置による加 工や CNC 工作機械による加工年がある。しかし，な らい装置による加工ではならいモデルが必要なため, 加工形状の多様性等に問題がある。また, CNC工作 機械はだ円加工機としては高価な装置である。 そこで今回, 構造が単純で, だ円チャックにおける

\footnotetext{
* 原稿受付 2006 年 8 月 25 日.

*1 正員, 山形大学工学部 (画992-8510 米沢市城南 4-3-16).

*2 正員, Conical Gear 技術研究所 (⿶992-8510 米沢市城南 43-16).

*3 学生員, 山形大学大学院理工学研究科.

E-mail : hkomatsu@yz.yamagata-u.ac.jp
}

問題を克服した新しいだ円切削装置を提案する.

新しいだ円切削装置は，だ円チャックにおける問題 を次のように克服する.この新しいだ円切削装置で は, 工具および被削物に回転運動を与えることにより だ円を切削する.その結果, スライダ機構を用いてい ないため, スライダと溝の摩擦が発生しない. また, 被削物にフラフープ運動をさせないため, これによる 振動が生じない.

本論文では，だ円切削装置の新しいだ円創成法を提 唱し，これに基づいて試作した装置によるだ円の切削， 測定の結果を報告する。

\section{2. だ円創成法}

だ円切削装置は二つの回転運動によりだ円を創成す る.その原理は固定両スライダ機構から連鎖の交替に よって得られる。

ここでは，まず固定両スライダ機構の原理について 述べる.それから固定軌跡 $\Gamma_{f}$ と移動軌跡 $\Gamma_{m}$ に着目 する.そして, 固定軌跡 $\Gamma_{f}$ と移動軌跡 $\Gamma_{m}$ を内歯歯 車と平歯車に置換えて考える，以上のようにして，固 定両スライダ機構から新しいだ円創成法までの過程を 示す.

$2 \cdot 1$ 固定両スライダ機構 図1に固定両スライ 
ダ機構を示す。固定節 C上に直交する直線溝が設け てあり, 直線溝には二つのスライダ A, B が置かれて いる.この二つのスライダ A, B は, 連接棒 D に対し 回り対偶により連結されている. 連接棒 D はスライ ダ $\mathrm{A}, \mathrm{B}$ ，固定節 $\mathrm{C}$ のそれぞれに対し，1回転すること ができる.

次に, この固定両スライダ機構において, 固定節 C 上に静止座標系 $o^{-} x y$ を固定する。これを図 2 に示 す.また連接棒 $\mathrm{D}$ 上に, 点 $\mathrm{A}_{0}$ から距離 $l$ の位置に点 $\mathrm{P}$ をる。すると, 点 $\mathrm{P} の$ 座標は式 $(1)$ となる。ま た, 点 $\mathrm{P}$ の軌跡は長半径 $L+l$, 短半径 $l$ のだ円とな る.だ円の式は式 ( 2 )である.

$$
\begin{aligned}
& P\left(x_{P}, y_{P}\right)\left\{\begin{array}{l}
x_{P}=(L+l) \cos \theta \\
y_{P}=l \sin \theta
\end{array}\right\} \\
& \left(\frac{x_{P}}{L+l}\right)^{2}+\left(\frac{y_{P}}{l}\right)^{2}=1 \ldots \ldots \ldots . .
\end{aligned}
$$

なお，ここで使用する記号は次のとおりである.

$L:$ 点 $\mathrm{A}_{0}, \mathrm{~B}_{0}$ 間の距離

$l:$ 点 $\mathrm{P}, \mathrm{A}_{0}$ 間の距離

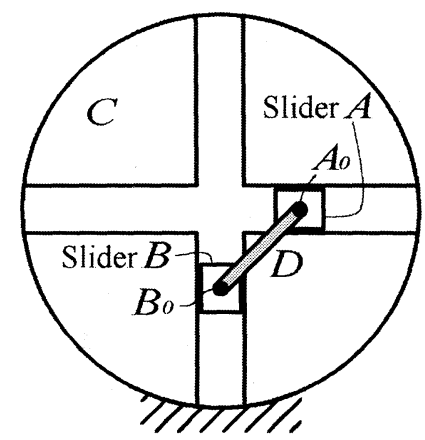

Fig. 1 Fixed block double-slider crank mechanism

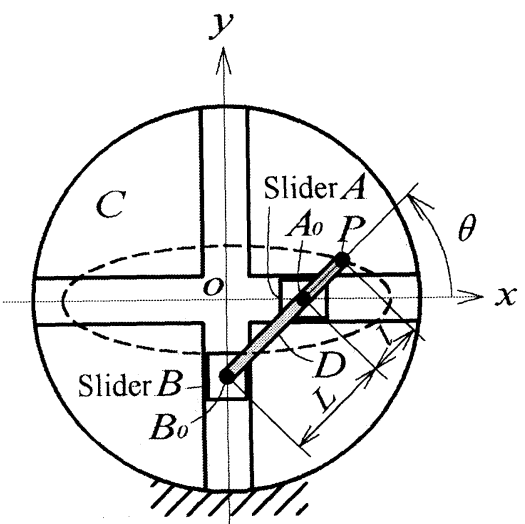

Fig. 2 Path of point $P$ in fixed block double-slider crank mechanism $\theta$ : スライダ A に対する連接棒 D の回転角

\section{$2 \cdot 2$ 瞬間中心 $\mathrm{Q}$ の固定軌跡 $\Gamma_{f}$ と移動軌跡 $\Gamma_{m}$}

図 3 におらいて, 連接棒 D の瞬間中心を点 $\mathrm{Q}$ とする. 静止座標系 $o^{-} x y$ におる瞬間中心 $\mathrm{Q}$ の座標は式 ( 3 ) となる.このため, 瞬間中心 $\mathrm{Q}$ を静止座標系でと らえた軌跡は式 (4) となり, 点 $\mathrm{O}$ を中心する半径 $L$ の円となる。これを瞬間中心 $\mathrm{Q}$ の固定軌跡 $\Gamma_{f}$ と呼 ぶ.

次に, 連接棒 $\mathrm{D}$ 上に動座標系 $\mathrm{B}_{0}-X Y$ を固定する。 この動座標系でとらえた瞬間中心 $\mathrm{Q}$ の座標は式 (5) となる。そして瞬間中心 $\mathrm{Q}$ を動座標系 $\mathrm{B}_{0}-X Y$ でと らえた軌跡は式 ( 6 ) となり, 中心 $(L / 2,0)$, 半径 $L / 2$ の円となる。これを瞬間中心 $\mathrm{Q}$ の移動軌跡 $\Gamma_{m}$ と呼 ぶ. 移動軌跡の中心 $(L / 2,0)$ を点 $\mathrm{M}$ とおく.

図 3 に瞬間中心 $\mathrm{Q}$ の固定軌跡 $\Gamma_{f}$ と移動軌跡 $\Gamma_{m}$ を 示す.

$$
\begin{aligned}
& Q\left(x_{Q}, y_{Q}\right)\left\{\begin{array}{l}
x_{Q}=L \cos \theta \\
y_{Q}=-L \sin \theta
\end{array}\right\} \\
& \therefore \quad x_{Q}^{2}+y_{Q}^{2}=L^{2} \\
& Q\left(X_{Q}, Y_{Q}\right)\left\{\begin{array}{l}
X_{Q}=x \cos \theta=L \cos ^{2} \theta \\
Y_{Q}=-x \sin \theta=-L \sin \theta \cos \theta
\end{array}\right\} \\
& \therefore \quad\left(X_{Q}-\frac{L}{2}\right)^{2}+Y_{Q}^{2}=\left(\frac{L}{2}\right)^{2}
\end{aligned}
$$

$2 \cdot 3$ 固定軌跡 $\Gamma_{f}$ と移動軌跡 $\Gamma_{m}$ の運動 一般 に, 瞬間中心の移動軌跡 $\Gamma_{m}$ は固定軌跡 $\Gamma_{f}$ に対して 転がり接触する. 固定両スライ夕゙機構において, 連接 棒 D がスライダ A に対して反時計回りに 1 回転する とき, 移動軌跡 $\Gamma_{m}$ が固定軌跡 $\Gamma_{f}$ の内側を瞬間中心 $\mathrm{Q}$ に常に接しながら転がり, 回転する。またこの間に,

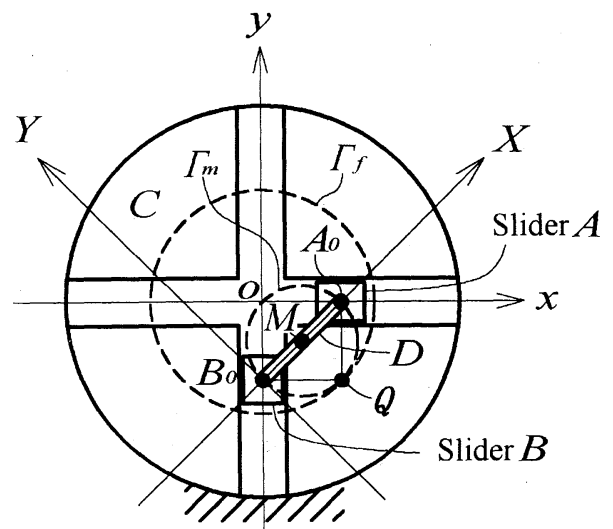

Fig. 3 Moving centrode and fixed centrode of fixed block double-slider crank mechanism 

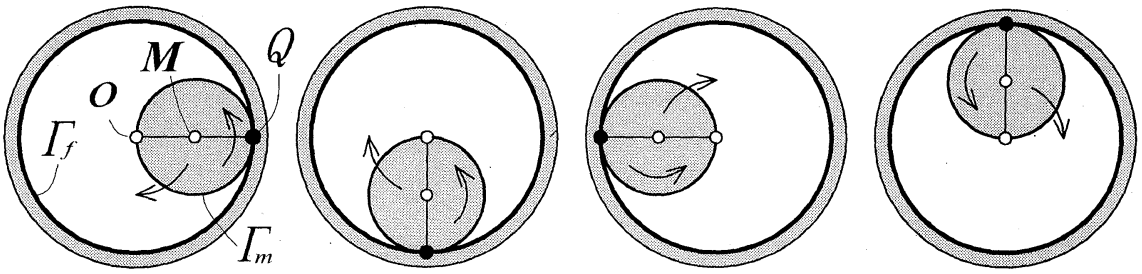

Fig. 4 Motion of moving centrode to fixed centrode

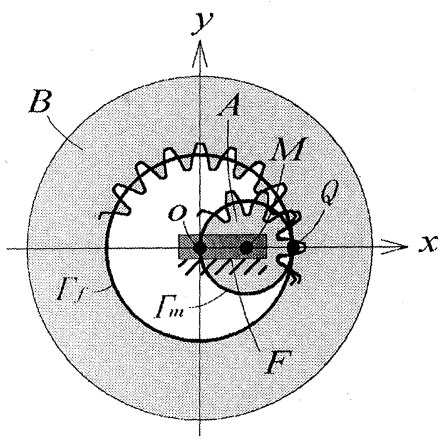

Fig. 5 Internal and spur gears mechanism

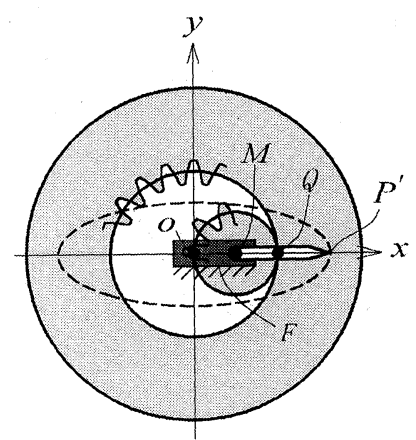

Fig. 6 Path of point $\mathrm{P}^{\prime}$ describing on internal gear of internal and spur gear mechanisms

$\Gamma_{m}$ 上の接触点 $\mathrm{Q}$ は移動軌跡 $\Gamma_{m}$ の円周を 2 周し, $\Gamma_{m}$ 上の接触点 $\mathrm{Q}$ は固定軌跡 $\Gamma_{f}$ の円周を 1 周する。その ようすを図 4 に示す.

この固定軌跡 $\Gamma_{f}$ と移動軌跡 $\Gamma_{m}$ の相対運動は, 次 のようにして実現することができる、まず，固定軌跡 $\Gamma_{f}$ の中心 0 と, 移動軌跡 $\Gamma_{m}$ の中心 $\mathrm{M}$ を固定する. そして, 固定軌跡 $\Gamma_{f}$ を 1 回転させ, 移動軌跡 $\Gamma_{m}$ を 2 回転させる，このとき，点 $\mathrm{Q}$ は転がり接触のときと同 様に移動軌跡 $\Gamma_{m}$ 上を 2 周し, 固定軌跡 $\Gamma_{f}$ 上を 1 周 する。

$\mathbf{2 \cdot 4}$ だ円切削装置の原理 $2 \cdot 3$ 節では, 固定両ス ライダ機構における移動軌跡 $\Gamma_{m}$ の固定軌跡 $\Gamma_{f}$ に対

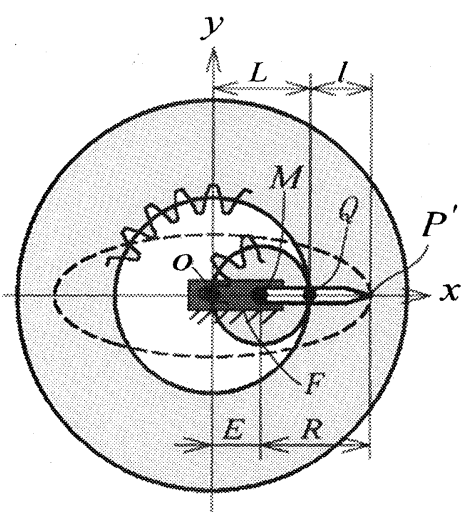

Fig. 7 Dimensions of internal and spur gears mechanisms

する相対運動が, 固定軌跡 $\Gamma_{f}$ と移動軌跡 $\Gamma_{m}$ のそれ ぞれの回転中心を固定して, 角速度比 $1: 2 て ゙$ 回転さ せることで実現できることを述べた。

ここで, 固定軌跡 $\Gamma_{f}$ を内歯歯車 $\mathrm{B}$ のピッチ円に対 応させ, 移動軌跡 $\Gamma_{m}$ を平歯車 $\mathrm{A}$ のピッチ円に対応さ せる.そして, 内歯歯車 $\mathrm{B}$ と平歯車 $\mathrm{A}$ の中心を固定 節 F で回り対偶により連結すると, 図 5 に示すような 機構として表すことができる。

この機構において, 固定両スライダ機構における固 定節 C は内歯歯車 $\mathrm{B}$ に相当し, 連接棒 D は平歯車 $\mathrm{A}$ のピッチ円の直径に相当する。 また，連接棒 D の延長 上の点 $\mathrm{P}$ は, 平歯車のピッチ円の直径上の点 $\mathrm{P}^{\prime}$ に相 当する.ここで, 内歯歯車を $\omega$ で回転させると平歯車 は $2 \omega$ で回転する. 平歯車のピッチ円の直径の延長上 の点 $\mathrm{P}^{\prime}$ は内歯歯車上に固定した平面上にだ円を描く.

これを図 6 に示す.

だ円切削装置では, 内歯歯車に固定した平面 $\left(0^{-} x y\right.$ 座標系)をワークに対応させる.また平歯車のピッチ 円の直径上に固定した直線上の点 $\mathrm{P}^{\prime}$ をバイトの歯先 に対応させる.このようにしてだ円切削装置はだ円を 創成する。

図 7 に示すように, バイトの回転中心からバイトの 歯先までの距離を $R$, ワークとバイトの回転中心間の 
オフセットを $E$ とおくと, 式 (6)，（7）および式( 8 ) より,だ円切削装置が切削するだ円の式は式 (9) とな る.式（9）のように，だ円切削装置が切削するだ円は 長半径が $R+E$, 短半径が $R-E$ となる.

$$
\begin{aligned}
& L=2 E \\
& l=R-E \ldots \ldots \ldots \ldots \ldots \ldots \ldots \ldots \ldots \ldots \ldots \ldots \ldots \ldots \ldots \ldots \ldots \ldots \ldots \ldots \ldots \ldots \\
& \therefore \quad\left(\frac{x}{R+E}\right)^{2}+\left(\frac{y}{R-E}\right)^{2}=1
\end{aligned}
$$

\section{3. だ円切削装置の設計および試作}

図 8 にだ円切削装置の試作機の概略図を示し，図 9 に実際に試作しただ円切削装置を示す。バイト側の軸 をバイト軸，ワーク軸の軸をワーク軸と呼ぶことにす る、ワーク軸とバイト軸はサーボモータで駆動されて おり，この二つのサーボモー夕は同じ回転数になるよ うにコントローラで制御されている。そして，サーボ モータには減速機が取付けられており, ワーク軸側の 減速比が $1 / 10$, バイト軸側の減速比が $1 / 5$ となってい る。そのため, ワーク軸とバイト軸は角速度比 $1: 2$ で回転する。また回転初期位置は常に一致するよう制 御している.

バイト軸とワーク軸の二軸間のオフセットおよび切

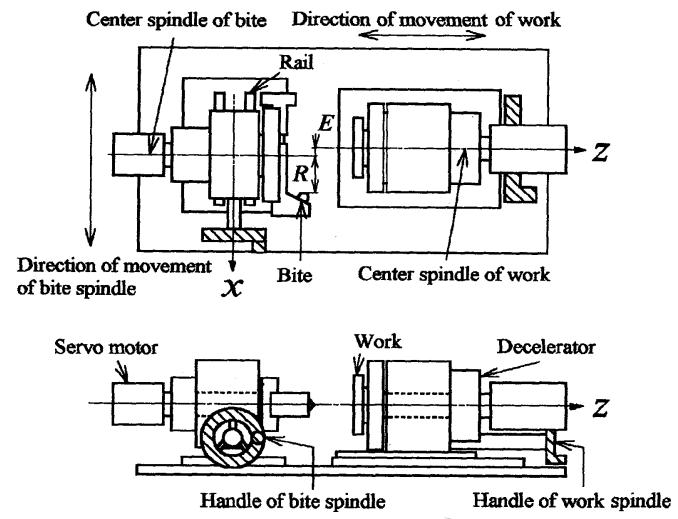

Fig. 8 Schematic view of a new cutting machine

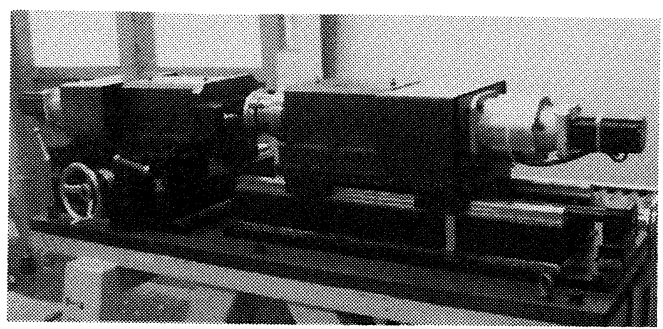

Fig. 9 A new elliptic machine
込み量は,バイト軸ハンドルで任意に調整できる。ま た,ワークの送り量は, ワーク軸ハンドルで任意に調 整することができる。

$3 \cdot 1$ バイトすくい角の変化 だ円切削装置では, だ円切削中にすくい角および逃げ角が変化する。ここ では，すくい角の変動について述べる，図 10 に示す ように, バイト軸回転角を $2 \theta$, ワーク軸回転角を $\theta$ とする。またバイトは初期位置 $\theta=0$ で，すくい角 $\phi$ =0 とする.ここで, ワークに固定した座標系 $\mathrm{B}_{0}-x y$ において, 点 $\mathrm{P}\left(x_{P}, y_{P}\right)$ における法線の傾き $\tan \varphi$ は 式(10)となる.

$\tan \varphi=-\frac{\mathrm{d} x}{\mathrm{~d} y}=\frac{(R+E)^{2} y_{P}}{(R-E)^{2} x_{P}}$

式(10)よりすくい角 $\phi$ は式(11) となる.

$$
\phi=\varphi-\theta
$$

図 $11 に E=0.5 \mathrm{~mm}, R=45.5 \mathrm{~mm}$ の場合のすく い角の変化を示す.

$3 \cdot 2$ だ円切削装置で切削されるだ円 2 章で示

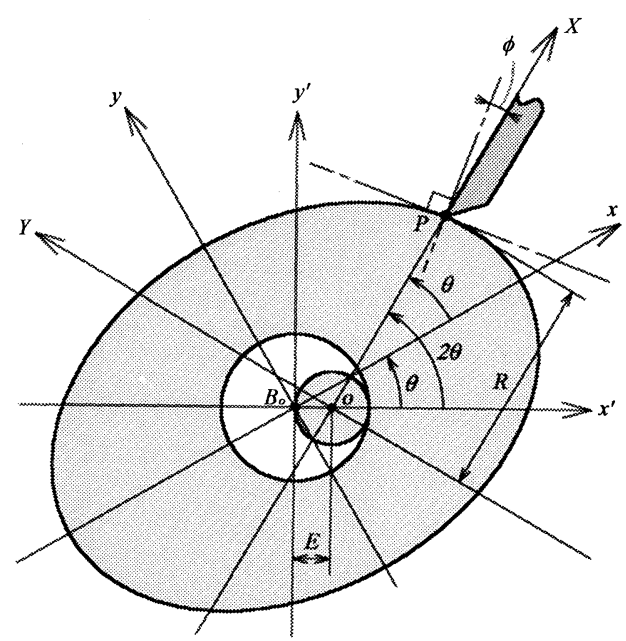

Fig. 10 Relative position of cutter to work

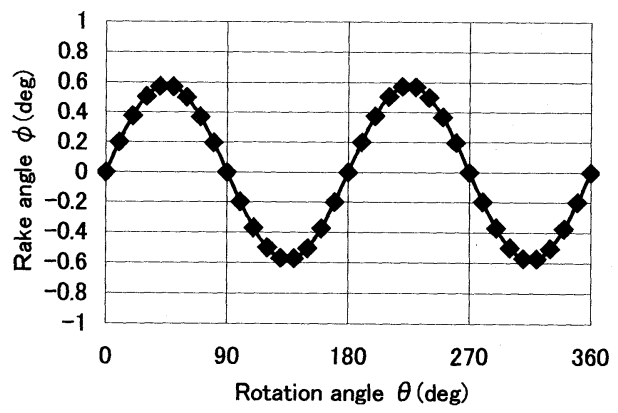

Fig. 11 Rake angle deviation 
したように，だ円切削装置が切削するだ円は式 $(9)$ と なる，だ円切削装置はバイト軸とワーク軸間のオフセ ット $E$ を変化させることで, 任意の切削をすること ができる。しかし，オフセット $E$ のみ変化させた場 合のだ円の変化は図 12 のようになる。ワークは図 12 の網掛け部分の形状に仕上がる.したがって,オフセ ット $E$ のみ変化させて切削しても, 正だ円形状に仕 上がらない.

次に長径を一定にし，短径のみ変化させた場合を考 えるこのときのだ円の変化は図 13 のようになる. このように，だ円切削装置でだ円を切削するには，長 径を一定とするように, オフセット $E$ とバイトの中 心から歯先までの距離 $R$ の両方を変化させる必要が ある。

\section{4. 実 験 検 証}

本研究で設計・試作しただ円切削装置を用いて，実

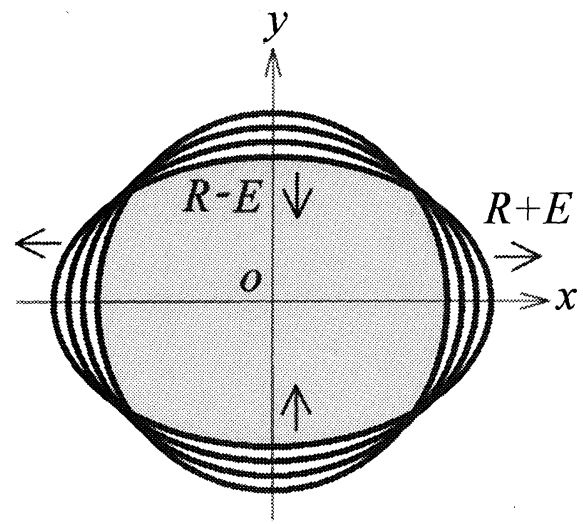

Fig. 12 Change of ellipse when only offset $E$ is changed

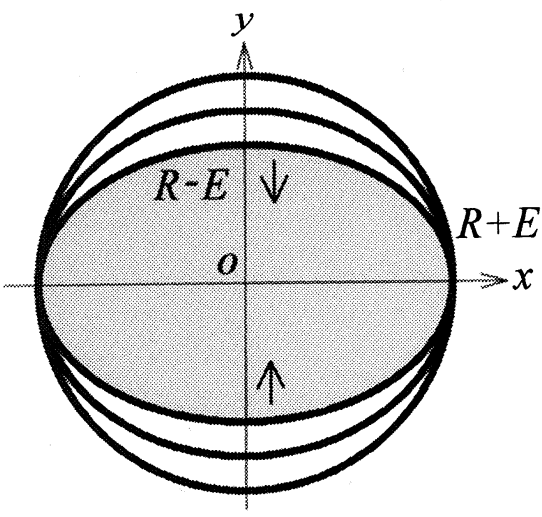

Fig. 13 Change of ellipse when both offset $E$ and distance $R$ are changed
際にだ円の製作を行った。今回は，長半径と短半径の 差 $2 E$ が $2 E=0.4 \mathrm{~mm}, 1.0 \mathrm{~mm}$ の 2 種類のだ円を製 作した。だ円切削中の写真を図 14 に示す。また, 試 作しただ円を図 15 に示す。なお，試作しただ円の長 半径はどちらも $95 \mathrm{~mm}$ である。表 1 に試作しただ円 の材質と切削条件を示す.

試作しただ円の精度を検証するため, 真円度測定機 を用いて真円度の測定を行った。一般に, 真円度測定 機は半径法を用いたものである，真円度測定機でだ円 を測定することにより，そのだ円の長半径と短半径の 差 $L$ を求めることができる. 表 2 に試作しただ円の 長半径と短半径の差 $L$ の理論值と測定値を示す。ま

Table 1 Material and cutting dimensions

\begin{tabular}{|c|c|}
\hline Material & A5056 \\
\hline Byte spindle rotational speed & $600 \mathrm{rpm}$ \\
\hline Work spindle rotational speed & $300 \mathrm{rpm}$ \\
\hline Rake angle (in case of $E=0$ ) & $4^{\circ}$ \\
\hline
\end{tabular}

Table 2 Theoretical and measured $L$

\begin{tabular}{|c|c|c|}
\hline $2 \mathrm{E}$ & Theoretical $L$ & Measured $L$ \\
\hline $0.4 \mathrm{~mm}$ & $0.4 \mathrm{~mm}$ & $0.43 \mathrm{~mm}$ \\
\hline $1.0 \mathrm{~mm}$ & $1.0 \mathrm{~mm}$ & $1.02 \mathrm{~mm}$ \\
\hline
\end{tabular}

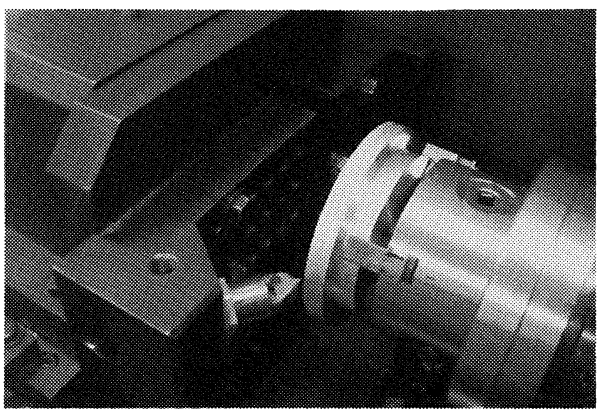

Fig. 14 Cutting of test elliptical cylinder

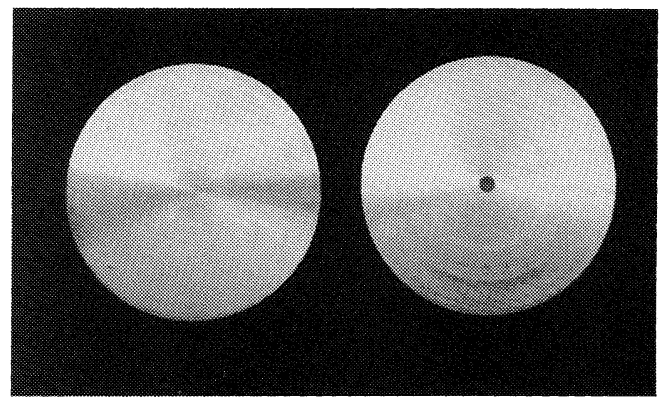

Fig. 15 Test elliptical cylinders 


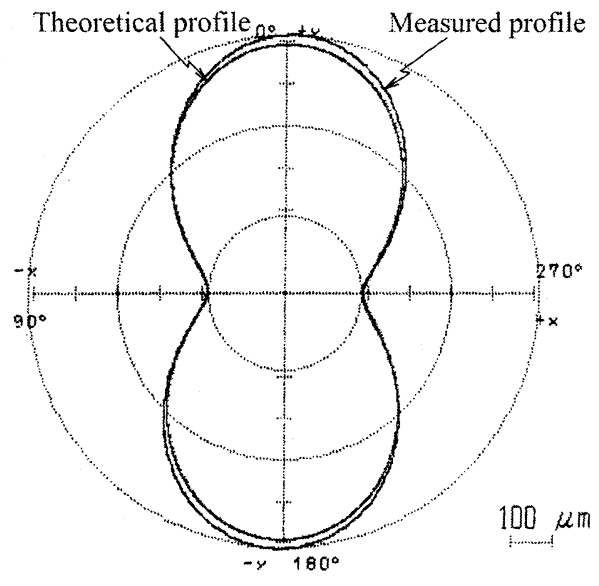

Fig. 16 Deviation from circular form $(2 E=0.4 \mathrm{~mm})$

た，真円度測定結果を図 16 および図 17 に示す.真円 度測定結果より, 長半径と短半径の差 $L$ の理論値と 測定値の差が $2 E=0.4 \mathrm{~mm}$ で $0.03 \mathrm{~mm}, 2 E=1.0$ $\mathrm{mm}$ で $0.02 \mathrm{~mm}$ であった.この誤差は, 初期設定に おけるモー夕軸とワーク軸のミスアライメントに起因 していると考えられる。そのためモー夕軸とワーク軸 のミスアライメントを測定したところ, 約 $10 \mu \mathrm{m}$ のミ スアライメントが存在していた。

しかし，ほぼ理論どおりのだ円が切削されており， 本だ円切削装置の有効性を証明している.

\section{5. 結言}

（1）構造が単純で, だ円チャックにおける問題を 克服する新しいだ円切削装置を考案した。この新しい だ円切削装置は, ワークと工具をともに回転させるこ とによりだ円を創成する。この原理は，固定両スライ ダ機構から連鎖の交替によって得られる。この固定両 スライダ機構から新しいだ円創成法までの過程を示し た.

（2）だ円創成法のこの原理を用いて，だ円切削装 置を試作した。そして, 試作しただ円切削装置を用い

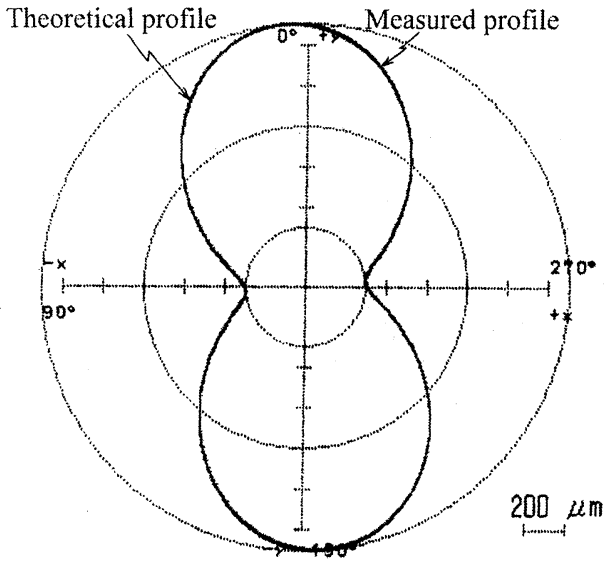

Fig. 17 Deviation from circular form $(2 E=1.0 \mathrm{~mm})$

てだ円を切削した。試作しただ円を真円度測定機を用 いて測定した. 試作しただ円の測定値は理論值と一致 しており，本だ円切削装置の有効性を証明している。

（3）新しいだ円切削装置は, 構造が簡素でかつ高 精度のだ円が切削できるため, 実用化の可能性を持っ ている。

終わりに, 本研究には本学の多くの大学院生および 卒業研究生が参加してきた。これら各位に対して心か ら感謝する。

\section{文献}

(1) Reuleaux, F. (Kennedy, A. B. W. trans.), The Kinematics of Machinery, (1963), p. 315, Dover.

(2) Komatsubara, H. and Mitome, K., Motion Analysis and Statics of Oldham Coupling, Transactions of the Japan Society of Mechanical Engineers, Series C, Vol. 71, No. 704 (2005), pp. 1384-1391.

(3) Mitome, K. et al., Development of Elliptical Chuck, Proceedings of the Touhokui Branch Ishinomaki Meeting of the Japan Society of Mechanical Engineers, No. 941, No. 2 (1994-9), pp. 305-307.

(4) Tanaka, M., Development of High Speed CNC Machine for Piston O.D. Finish, Internal Combustion Engine, Vol. 29, No. 374 (1990), pp. 72-80. 